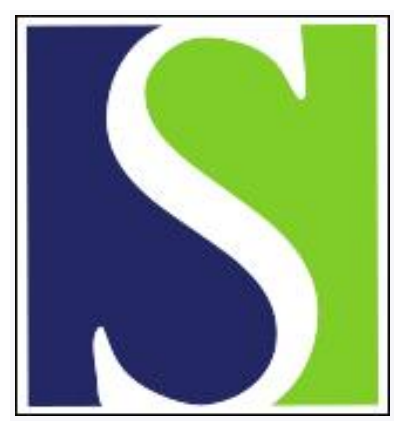

Scand J Work Environ Health 2002;28(1):33-41

https://doi.org/10.5271/sjweh.644

Issue date: Feb 2002

Prevalence of self-reported hypersensitivity to electric or magnetic fields in a population-based questionnaire survey

by Hillert L, Berglind N, Arnetz BB, Bellander T

Affiliation: Department of Environmental Health, Norrbacka/Karolinska Hospital, SE-171 76 Stockholm, Sweden. lena.hillert@medhs.ki.se

Refers to the following texts of the Journal: 1997;23 suppl 3:65-67 1995;21(5):325-334

Key terms: allergy; cross-sectional study; electric fields; hypersensitivity to electricity; magnetic fields; population-based questionnaire survey; prevalence; self-assessment; self-report; self-reported hypersensitivity; symptom

This article in PubMed: www.ncbi.nlm.nih.gov/pubmed/11871850 


\title{
Prevalence of self-reported hypersensitivity to electric or magnetic fields in a population-based questionnaire survey
}

\author{
by Lena Hillert, MD, ${ }^{1,2}$ Niklas Berglind, BSocSc, ${ }^{1}$ Bengt B Arnetz, MD, ${ }^{3}$ Tom Bellander, PhD ${ }^{1,4}$
}

\begin{abstract}
Hillert L, Berglind N, Arnetz BB, Bellander T. Prevalence of self-reported hypersensitivity to electric or magnetic fields in a population-based questionnaire survey. Scand J Work Environ Health 2002;28(1):33-41.

Objectives The prevalence of medically unexplained symptoms attributed to exposure to electromagnetic fields is still largely unknown. Previous studies have investigated reported hypersensitivity to electricity in selected groups recruited from workplaces or outpatient clinics. The aim of this study was to estimate the prevalence of self-reported hypersensitivity to electric or magnetic fields in the general population and to describe characteristics of the group reporting such hypersensitivity with regard to demographics, other complaints, hypersensitivities, and traditional allergies.

Methods A cross-sectional questionnaire survey was conducted in 1997 among 15000 men and women between 19 and 80 years of age in Stockholm County. The response rate was $73 \%$.

Results One and a half percent of the respondents reported hypersensitivity to electric or magnetic fields. Prevalence was highest among women and in the 60- to 69-year age group. The hypersensitive group reported all symptoms, allergies, and other types of hypersensitivities included in the survey (as well as being disturbed by various factors in the home) to a significantly greater extent than the rest of the respondents. No specific symptom profile set off the hypersensitive group from the rest of the respondents.

Conclusions The results should be interpreted with caution. But they suggest that there is widespread concern among the general population about risks to health posed by electric and magnetic fields. More research is warranted to explore ill health among people reporting hypersensitivity to electric or magnetic fields.
\end{abstract}

Key terms allergy, cross-sectional, hypersensitivity to electricity, symptoms.

Electricity is essential to many of modern society's new and developing technologies. Ever-emerging inventions and applications offer conveniences and benefits. But there are also frequent warnings and words of caution. Exposure to electromagnetic fields is suspected of causing acute and chronic health problems. In 1998, a working group of the National Institute of Environmental Health Sciences (NIEHS) (1) in the United States classified extremely low-frequency electric and magnetic fields as possibly carcinogenic to humans. Acute health effects have been cited, but controlled experiments have been unable so far to establish any direct causal link between exposure to electric or magnetic fields below recommended reference levels and self-reported symptoms (2).
There are thus currently no diagnostic criteria or validated tests available to establish "hypersensitivity" to electric or magnetic fields. The use of the syndrome label "hypersensitivity to electricity" is based on peoples' own experience that their symptoms are triggered or aggravated when they are in the vicinity of electrical equipment (3). In Sweden, work that involves a visual display unit (VDU) has been one of the most commonly reported triggering factors, while environmental exposure to outdoor sources such as power lines is a factor frequently cited by afflicted individuals in central Europe (2).

There is significant overlap in the reported symptoms of various environmental syndromes, including hypersensitivity to electricity (4), multiple chemical

1 Department of Environmental Health, Norrbacka/Karolinska Hospital, Stockholm, Sweden.

2 Division of Occupational Medicine, Department of Public Health Sciences, Karolinska Institutet, Stockholm, Sweden.

3 Section of Social Medicine, Department of Public Health and Caring Sciences, Uppsala University, Uppsala, Sweden.

4 Division of Environmental Epidemiology, Institute of Environmental Medicine, Karolinska Institutet, Stockholm, Sweden.

Reprint requests to: Dr Lena Hillert, Department of Environmental Health, Norrbacka/Karolinska Hospital, SE-171 76 Stockholm, Sweden. [E-mail: lena.hillert@medhs.ki.se] 
sensitivity $(5,6)$, amalgam-related complaints $(7,8)$ and sick-building syndrome (9). A common label, such as "medically unexplained symptoms", has been suggested (10). But a multidimensional description — including symptom profiles, attributions, time aspects, and behavioral changes - is needed to understand these complex phenomena (11). It is not uncommon that a person reports more than one type of environmental illness. A significant overlap between persons who report hypersensitivity to electricity and those with amalgam-related complaints (symptoms attributed to the leakage of mercury from dental restorations) has been observed in Sweden (12).

In a population-based California survey, $6.3 \%$ of the respondents reported physician-diagnosed environmental illness or multiple chemical sensitivity (MCS) (13). The authors suggested that the homogeneity of responses across different subgroups was due to either a common physiological response or widespread apprehension about chemical exposure.

The prevalence of perceived hypersensitivity to electricity and the possible coexistence of various types of environmental illness is largely unknown. A self-help group called the Swedish Association for the ElectroSensitive has about 2000 members, but information released by trade unions suggests that the incidence of reported hypersensitivity to electricity is much greater (14).

The first aim of this study was to estimate the prevalence of self-reported hypersensitivity to electric and magnetic fields. The second aim was to explore the association of such hypersensitivity with demographic characteristics, other complaints and types of self-reported hypersensitivity (including traditional allergies).

\section{Subjects and methods}

Information about allergies and hypersensitivities was obtained from a cross-sectional questionnaire survey on environmental health in Stockholm County during 1997. The questionnaire also included questions about education, living arrangements, complaints, symptoms, and reported disturbances due to environmental factors. There were 87 questions. Information on age, gender, income, and country of birth was obtained from the national population register.

The questionnaires (including written information concerning confidentiality and intended use of the data) were mailed by Statistics Sweden to 15000 randomly selected adults (ages 19-80 years) of the 1.3 million members of this age group residing in the county. Subjects were selected from 17 different geographic strata to ensure the most reliable possible information on the distribution of health problems among different areas of Stockholm, including those exposed to airport noise and heavy traffic (table 1). After as many as three written reminders, 10670 persons returned the questionnaire a response rate of $73 \%$ (excluding persons identified as unknown by the post office). The response rate varied among different groups [eg, with regard to country of birth (from $59 \%$ for persons from non-European countries to $75 \%$ for persons born in Sweden), gender $(68 \%$ for men and $77 \%$ for women), and age (from $70 \%$ of the 19 - to 39 -year age group to $77 \%$ of the 60 - to 80 year age group). There were 65 respondents for whom information on either gender or age was unavailable.

In two questions, the respondents were asked to check all factors for which they were hypersensitive or allergic. The alternatives were furry animals, pollen, dust, mold, mite, food, gluten, amalgam, dental fillings other than amalgam, electric or magnetic fields, nickel, cosmetics, and an open-ended alternative. There were no further questions on triggering factors or functional handicap due to hypersensitivity to electric or magnetic fields. Our analyses compared persons who reported hypersensitivity to electric or magnetic fields (the hypersensitivity group) in this question to respondents who did not report this syndrome. We also compared the distribution of traditional allergies, other hypersensitivities,

Table 1. Selection criteria, sample size, and response rate for groups included in a questionnaire survey of the Stockholm County general population (ages 19-80 years) in 1997.

\begin{tabular}{|c|c|c|c|}
\hline Selection criteria & $\begin{array}{l}\text { Source population } \\
\qquad(\mathrm{N})\end{array}$ & $\begin{array}{l}\text { Sample size } \\
\text { (N) }\end{array}$ & $\begin{array}{l}\text { Response rate } \\
\quad(\%)\end{array}$ \\
\hline $\begin{array}{l}\text { Home address within } 50 \text { meters of streets with heavy traffic (noise level }>71 \mathrm{dBA} \text { ) in the inner } \\
\text { city of Stockholm }\end{array}$ & 32580 & 3000 & 71 \\
\hline Home address in 1 of 12 geographic parts of the city of Stockholm & 513184 & 6000 & 72 \\
\hline Home within area exposed to at least a noise level of $55 \mathrm{dBA}$ from the Arlanda or Bromma Airport & 18272 & 500 & 71 \\
\hline $\begin{array}{l}\text { Home address in area of increased noise due to traffic (cars or trains) in Sollentuna (a city in the } \\
\text { northern part of the greater Stockholm area) }\end{array}$ & 3122 & 500 & 77 \\
\hline Home address in other parts of Sollentuna & 36815 & 500 & 77 \\
\hline Home address in other parts of Stockholm County & 689425 & 4500 & 74 \\
\hline Overall & 1293398 & 15000 & 73 \\
\hline
\end{tabular}


and reported disturbances due to environmental factors with those of groups that reported asthma or hay fever, and also, in some cases, with the subgroup reporting amalgam-related symptoms and hypersensitivity to electric or magnetic fields. We investigated possible symptom indices by means of a factor analysis for referents and the cases of reported hypersensitivity to electric or magnetic fields. Replicated factor structures provided evidence for the construct validity of indices that could serve as key tools for comparing groups in future studies.

The ethics committee of the Karolinska Hospital reviewed the study design and judged that a formal approval was not required for the study.

\section{Statistical methods}

The descriptive analyses applied inverse probability weights based on the stratified sampling method. Except for the demographic data in tables 1 and 2, prevalence is shown as standardized rates using the nonhypersensitive group as a standard population regarding age and gender. Proportions and 95\% confidence intervals $(95 \% \mathrm{CI})$ are presented. The chi-square test was used to test for independence between variables, a Pvalue of less than 0.05 being regarded as statistically significant.

We used factor analysis to investigate possible underlying patterns of symptoms. We submitted all symptoms, which were scored on a frequency scale of $1-3$, to an exploratory factor analysis. We analyzed two groups, referents not reporting hypersensitivity to electric or magnetic fields and those reporting hypersensitivity to electric or magnetic fields. The Kaiser-Guttman Rule (eigenvalue $>1$ ) was used to determine the number of factors that should be retained for rotation. Only items with loadings in excess of 0.4 were considered. We used the Cronbach alpha coefficients to assess the internal consistency of extracted factors.

\section{Results}

\section{Demographic characteristics}

Of all the respondents, $1.5 \%$ (167 persons) reported hypersensitivity to electric or magnetic fields. Table 2 presents the proportion of various demographic groups that reported hypersensitivity to electric or magnetic fields and asthma or hay fever (hay fever or other allergic rhinitis), 2520 respondents reported having suffered from asthma or hay fever at least once. Information on gender and age was unavailable for one person who reported hypersensitivity to electric or magnetic fields and for 18 persons who reported asthma or hay fever. The prevalence of hypersensitivity to electric or magnetic fields was higher among the women than among the men (1.8\% as compared with $1.1 \%)$. The syndrome

Table 2. Prevalence of self-reported hypersensitivity to electric or magnetic fields and asthma or hay fever in various demographic groups. (EU = European Union, 95\% Cl = 95\% confidence interval)

\begin{tabular}{|c|c|c|c|c|c|}
\hline \multirow[t]{2}{*}{ Group } & \multirow{2}{*}{$\begin{array}{l}\text { Number in overall } \\
\text { study group }\end{array}$} & \multicolumn{2}{|c|}{ Hypersensitivity to electric or magnetic fields } & \multicolumn{2}{|c|}{ Asthma or hay fever } \\
\hline & & $\%$ & $95 \% \mathrm{Cl}$ & $\%$ & $95 \% \mathrm{Cl}$ \\
\hline Overall prevalence & 10605 & 1.5 & $1.2-1.8$ & 23.2 & $22.2-24.1$ \\
\hline \multicolumn{6}{|l|}{ Gender } \\
\hline Male & 4745 & 1.1 & $0.8-1.5$ & 21.7 & 20.3-23.1 \\
\hline Female & 5860 & 1.8 & $1.4-2.2$ & 24.4 & $23.1-25.7$ \\
\hline \multicolumn{6}{|l|}{ Age (years) } \\
\hline $19-39$ & 4372 & 1.2 & $0.9-1.7$ & 26.8 & $25.2-28.3$ \\
\hline $40-59$ & 3836 & 1.5 & $1.1-2.0$ & 22.0 & $20.5-23.6$ \\
\hline $60-80$ & 2397 & 1.8 & $1.3-2.6$ & 18.5 & 16.8-20.4 \\
\hline \multicolumn{6}{|l|}{ Country of birth } \\
\hline Sweden & 8963 & 1.3 & $1.1-1.6$ & 23.3 & 22.3-24.3 \\
\hline Other Nordic country & 576 & 1.4 & $0.7-3.0$ & 24.2 & 20.3-28.4 \\
\hline EU country besides Nordic countries & 482 & 2.3 & $1.2-4.6$ & 18.9 & $15.2-23.2$ \\
\hline Country outside EU & 584 & 2.8 & $1.7-4.8$ & 24.0 & $20.4-28.0$ \\
\hline \multicolumn{6}{|l|}{ Education (highest level) } \\
\hline $\begin{array}{l}\text { Comprehensive school or equivalent } \\
\text { (up to nine years) }\end{array}$ & 2909 & 1.4 & $1.0-2.0$ & 18.9 & 17.4-20.6 \\
\hline High school & 3857 & 1.3 & $0.9-1.8$ & 25.5 & $23.9-27.1$ \\
\hline University & 3246 & 1.7 & $1.2-2.3$ & 24.5 & $22.7-26.3$ \\
\hline \multicolumn{6}{|l|}{ Marital status } \\
\hline Married or living with partner & 6589 & 1.3 & $1.0-1.6$ & 22.5 & 21.4-23.7 \\
\hline Single & 3657 & 1.7 & $1.3-2.3$ & 24.5 & $22.8-26.2$ \\
\hline \multicolumn{6}{|l|}{ Income } \\
\hline USD $<15000$ & 4503 & 1.9 & $1.5-2.4$ & 24.2 & $22.8-25.6$ \\
\hline USD $\geq 15000$ & 5936 & 1.1 & $0.9-1.5$ & 22.3 & $21.1-23.6$ \\
\hline
\end{tabular}


was most common in the 60- to 80-year age group when all persons who reported hypersensitivity to electric or magnetic fields were considered. But if the subgroup of persons who also reported amalgam intolerance (53 persons in this subgroup, 185 having reported amalgam intolerance all told) was excluded, we observed a more uniform distribution among the different age groups. The proportion of persons who reported hypersensitivity to electric or magnetic fields was higher for persons born outside the Nordic countries and also for the lower income groups.

The proportion of persons on early retirement or disability pension was higher among those who report hypersensitivity to electric or magnetic fields than among all the referents (table 3 ). The differences in the distribution of persons on sick leave were smaller. The proportion of unemployed persons was significantly higher in the hypersensitivity group than in either of the reference groups.

\section{Symptom profile}

The most commonly reported symptom (of the 11 symptoms included in the question on symptoms and an additional question on skin symptoms) in the hypersensitivity group was fatigue, as was also the case in the reference groups (table 4). Symptoms, except for skin symptoms, were reported as being experienced "often or every week", "sometimes", or "never" during the last 3 months. In table 4 the proportions of respondents who reported the respective symptoms "often or every week" are presented. Based on the analyses of the three levels of reported frequency ("often or every week", "sometimes", "never"), all the symptoms were considerably more frequent among the persons who reported

Table 3. Distribution of employment status in the group reporting hypersensitivity to electric or magnetic fields ( $N=166$ ), all referents $(\mathrm{N}=10439)$, and referents with asthma or hay fever $(\mathrm{N}=2502)$, adjusted for age and gender. $(95 \% \mathrm{Cl}=95 \%$ confidence interval)

\begin{tabular}{|c|c|c|c|c|c|c|}
\hline \multirow[t]{3}{*}{ Employment status } & \multirow{2}{*}{\multicolumn{2}{|c|}{$\begin{array}{l}\text { Hypersensitivity } \\
\text { to electric or } \\
\text { magnetic fields }\end{array}$}} & \multicolumn{4}{|c|}{ Referents } \\
\hline & & & \multicolumn{2}{|c|}{ All referents } & \multicolumn{2}{|c|}{ Referents with asthma or hay fever } \\
\hline & $\%$ & $95 \% \mathrm{Cl}$ & $\%$ & $95 \% \mathrm{Cl}$ & $\%$ & $95 \% \mathrm{Cl}$ \\
\hline Working & 51.8 & $41.4-61.9$ & 61.1 & $59.9-62.2$ & 61.6 & $59.3-63.9$ \\
\hline Unemployed & 12.1 & $6.8-20.6$ & $4.4^{\star}$ & $4.0-4.9$ & $4.5^{\star}$ & $3.6-5.6$ \\
\hline On sick leave & 2.5 & $0.5-10.4$ & 1.6 & $1.4-1.9$ & 1.8 & $1.3-2.6$ \\
\hline On early retirement or disability pension & 7.7 & $4.1-14.1$ & $3.8^{\star}$ & $3.4-4.3$ & 4.8 & $3.9-6.0$ \\
\hline Retired & 9.7 & $5.8-15.8$ & 14.6 & $13.8-15.4$ & 10.6 & $9.2-12.1$ \\
\hline Other categories & 16.2 & $9.8-25.7$ & 14.4 & $13.6-15.2$ & 16.6 & 14.9-18.5 \\
\hline
\end{tabular}

${ }^{\star} \mathrm{P}<0.05$ in the comparison with the group reporting hypersensitivity to electric or magnetic fields.

Table 4. Prevalence of people who reported having complaints at least once a week during the last 3 months (skin complaints reported as experienced or not experienced during the last 12 months) in the groups of the respondents [hypersensitivity to electric or magnetic fields $(\mathrm{N}=166)$, all referents $(\mathrm{N}=10439)$, and referents with asthma or hay fever $(\mathrm{N}=2502)$ ], adjusted for age and gender. $(95 \% \mathrm{Cl}=95 \%$ confidence interval)

\begin{tabular}{|c|c|c|c|c|c|c|}
\hline \multirow[t]{3}{*}{ Complaint } & \multirow{2}{*}{\multicolumn{2}{|c|}{$\begin{array}{l}\text { Hypersensitivity } \\
\text { to electric or } \\
\text { magnetic fields }\end{array}$}} & \multicolumn{4}{|c|}{ Referents } \\
\hline & & & \multicolumn{2}{|c|}{ All referents } & \multicolumn{2}{|c|}{ Referents with asthma or hay fever } \\
\hline & $\%$ & $95 \% \mathrm{Cl}$ & $\%$ & $95 \% \mathrm{Cl}$ & $\%$ & $95 \% \mathrm{Cl}$ \\
\hline Facial skin problems (not acne vulgaris) a & 36.3 & $27.4-46.3$ & $13.4^{\star}$ & $12.6-14.2$ & $19.1^{*}$ & $17.3-21.1$ \\
\hline Eye irritation & 23.2 & $15.9-32.4$ & $5.6^{\star}$ & $5.1-6.2$ & $9.8^{*}$ & $8.4-11.3$ \\
\hline Runny or stuffy nose & 17.0 & $11.1-25.2$ & $8.7^{\star}$ & $8.1-9.4$ & 17.8 & $16.0-19.7$ \\
\hline Impaired sense of smell & 6.8 & $3.0-14.7$ & 3.8 & $3.4-4.3$ & 6.4 & $5.3-7.8$ \\
\hline Hoarse or dry throat & 13.7 & $8.4-21.6$ & $5.4^{\star}$ & $4.9-6.0$ & 9.9 & $8.5-11.4$ \\
\hline Coughing & 8.0 & $4.3-14.5$ & 5.0 & $4.6-5.6$ & 9.0 & $7.7-10.5$ \\
\hline Sense of pressure in ear & 6.2 & $3.0-12.3$ & $2.2^{\star}$ & $1.9-2.6$ & 3.4 & $2.6-4.4$ \\
\hline Fatigue & 45.5 & $36.0-55.4$ & $26.9^{\star}$ & $25.9-28.0$ & $34.8^{*}$ & $32.6-37.1$ \\
\hline Sense of heaviness in head & 24.6 & $17.3-33.9$ & $9.4^{\star}$ & $8.7-10.1$ & $13.5^{*}$ & $11.9-15.2$ \\
\hline Headache & 16.8 & $10.7-25.4$ & $9.1^{\star}$ & $8.4-9.8$ & 12.9 & $11.3-14.6$ \\
\hline Nausea or dizziness & 9.0 & $4.8-16.1$ & $3.6^{\star}$ & $3.1-4.0$ & 5.2 & $4.2-6.4$ \\
\hline Difficulties to concentrate & 14.1 & $8.8-21.8$ & $5.0^{\star}$ & $4.5-5.5$ & 7.5 & $6.3-8.9$ \\
\hline
\end{tabular}

a Experienced during the last 12 months.

${ }^{*} \mathrm{P}<0.05$ in the comparison with the group reporting hypersensitivity to electric or magnetic fields. 
hypersensitivity to electric or magnetic fields as compared with all the referents. In comparing the hypersensitivity group with referents with asthma or hay fever in this way, we observed a significant difference when it came to skin and eye complaints, impaired sense of smell, feeling of pressure in ear, heaviness in the head, nausea or dizziness, and difficulties in concentrating.

\section{Reported asthma, allergies, other types of hypersensi- tivities and disturbing factors}

The prevalence of reported asthma $[20.1 \%$ (95\% CI 13.3-29.1) for the hypersensitivity group and 9.5\% (95\% CI 8.9-10.2) for the referents], hay fever [27.4\% (95\% CI 19.4-37.2) for the hypersensitivity group and $18.4 \%$ (95\% CI 17.5-19.2) for the referents] and allergic conjunctivitis [31.8\% (95\% CI 23.3-41.7) for the hypersensitivity group and $15.3 \%$ (95\% CI 14.5-16.2) for the referents] was significantly higher for the persons who reported hypersensitivity to electric or magnetic fields than for all the referents. The group reporting both hypersensitivity to electric or magnetic fields and amalgam-related complaints had a slightly lower prevalence of asthma $(17.2 \%, 95 \%$ CI 8.5-31.8) and hay fever $(26.6 \%, 95 \%$ CI $14.9-42.8)$ than all the persons who reported hypersensitivity to electric or magnetic fields but a higher prevalence of allergic conjunctivitis $(36.1 \%$, 95\% CI 21.8-53.4). Reported allergies or hypersensitivities to furry animals, pollen, dust, mold, mite, food, gluten, amalgam, dental fillings other than amalgam, nickel, and cosmetics were significantly more frequent among the persons with hypersensitivity to electric or magnetic fields than among all the referents (table 5). The prevalence was especially high in the group reporting hypersensitivity to electric or magnetic fields and amalgam-related complaints, except for pollen. The only types of allergies more commonly reported among the referents with asthma or hay fever were those to furry animals and pollen.

Persons with hypersensitivity to electric or magnetic fields also reported being disturbed or affected by various nuisance factors in the home more often than all the referents (table 6).

\section{Common cold and hypertension}

The proportion of respondents in the hypersensitivity group who reported that they suffered from common colds more than twice a year was significantly larger than for all the referents [33.1\% (95\% CI 24.3-43.3) for the hypersensitivity group and $22.7 \%$ (95\% CI 21.8 23.7) for all the referents], but no difference emerged in comparison with the asthma-hay fever group. There was some indication of a higher prevalence of physician-diagnosed hypertension [18.4\% (95\% CI $12.3-$ 26.8 ) for the hypersensitivity group and $13.1 \%$ (95\% CI 12.3-13.9) for all the referents]. In the group that reported both hypersensitivity to electric or magnetic fields and amalgam-related symptoms, the prevalence was $28.4 \%$ (95\% CI 15.3-46.6) for common colds and $35.3 \%$ (95\% CI 21.3-52.4) for physician-diagnosed hypertension.

\section{Factor analysis}

We scored symptoms, except skin complaints, on a frequency scale of 1-3 [never, sometimes or often (every week)]. The respondents reported whether they had or had not experienced skin complaints during the past 12 months. We used the principal factor analysis model

Table 5. Prevalence of respondents in the groups that reported allergy and hypersensitivity [hypersensitivity to electric or magnetic fields ( $N=166)$, combined hypersensitivity to electric or magnetic fields and amalgam intolerance $(\mathrm{N}=53)$, all referents $(\mathrm{N}=10439)$, and referents with asthma or hay fever ( $\mathrm{N}=2502)]$, adjusted for age and gender. (95\% $\mathrm{Cl}=95 \%$ confidence interval)

\begin{tabular}{|c|c|c|c|c|c|c|c|c|}
\hline \multirow{3}{*}{$\begin{array}{l}\text { Source of allergy or } \\
\text { hypersensitivity }\end{array}$} & \multicolumn{4}{|c|}{ Hypersensitive to electric or magnetic fields } & \multicolumn{4}{|c|}{ Referents } \\
\hline & \multicolumn{2}{|c|}{ All } & \multicolumn{2}{|c|}{$\begin{array}{l}\text { Combined with amalgam } \\
\text { intolerance }\end{array}$} & \multicolumn{2}{|c|}{ All referents } & \multicolumn{2}{|c|}{$\begin{array}{c}\text { Referents with asthma } \\
\text { or hay fever }\end{array}$} \\
\hline & $\%$ & $95 \% \mathrm{Cl}$ & $\%$ & $95 \% \mathrm{Cl}$ & $\%$ & $95 \% \mathrm{Cl}$ & $\%$ & $95 \% \mathrm{Cl}$ \\
\hline Furry animal & 25.4 & $17.9-34.8$ & 39.0 & $24.5-55.8$ & $12.4^{\star}$ & $11.7-13.1$ & $39.4^{\star}$ & $37.2-41.8$ \\
\hline Pollen & 27.4 & $19.2-37.4$ & 24.5 & $12.8-41.8$ & $17.1^{\star}$ & $16.2-18.0$ & $62.4^{\star}$ & $60.0-64.7$ \\
\hline Dust & 39.9 & $30.9-49.8$ & 49.0 & $32.9-65.4$ & $12.8^{*}$ & $12.1-13.6$ & 35.4 & $33.2-37.7$ \\
\hline Mold & 35.0 & $26.2-44.9$ & 48.0 & $31.9-64.5$ & $5.6^{\star}$ & $5.1-6.2$ & $16.7^{\star}$ & $15.0-18.6$ \\
\hline Mite & 25.8 & 18.3-35.1 & 43.3 & $27.9-60.1$ & $3.7^{\star}$ & $3.3-4.1$ & $11.8^{\star}$ & $10.4-13.5$ \\
\hline Food & 21.5 & $14.8-30.2$ & 37.9 & $23.7-54.6$ & $7.0^{\star}$ & $6.4-7.6$ & 20.1 & $18.2-22.0$ \\
\hline Gluten & 13.4 & $8.3-21.0$ & 33.2 & $19.9-49.8$ & $0.5^{*}$ & $0.3-0.6$ & $0.9^{*}$ & $0.6-1.5$ \\
\hline Amalgam & 31.2 & $23.0-40.8$ & . & . & $1.3^{\star}$ & $1.0-1.5$ & $1.7^{\star}$ & $1.2-2.5$ \\
\hline Dental fillings other than amalgam & 13.6 & $8.4-21.3$ & 38.4 & $24.0-55.2$ & $0.5^{\star}$ & $0.3-0.7$ & $0.4^{\star}$ & $0.2-0.8$ \\
\hline Nickel & 32.0 & $23.6-41.6$ & 59.6 & $42.3-74.8$ & $9.4^{\star}$ & $8.7-10.0$ & $12.0^{\star}$ & $10.6-13.6$ \\
\hline Cosmetics & 39.0 & $30.0-48.8$ & 62.1 & $45.0-76.7$ & $8.9^{*}$ & $8.3-9.6$ & $15.8^{\star}$ & $14.1-17.6$ \\
\hline
\end{tabular}

${ }^{\star} \mathrm{P}<0.05$ in the comparison with the group reporting hypersensitivity to electric or magnetic fields. 
Table 6. Prevalence of respondents who reported being disturbed at least once a week in their home by each environmental factor [hypersensitivity to electric or magnetic fields ( $N=166)$, all referents $(\mathrm{N}=10439)$ and referents with asthma or hay fever $(\mathrm{N}=2502)$ ], adjusted for age and gender. (95\% $\mathrm{Cl}=95 \%$ confidence interval)

\begin{tabular}{|c|c|c|c|c|c|c|}
\hline \multirow[t]{3}{*}{ Reported disturbance } & \multirow{2}{*}{\multicolumn{2}{|c|}{$\begin{array}{l}\text { Hypersensitivity to electric } \\
\text { or magnetic fields }\end{array}$}} & \multicolumn{4}{|c|}{ Referents } \\
\hline & & & \multicolumn{2}{|c|}{ All referents } & \multicolumn{2}{|c|}{ Referents with asthma or hay fever } \\
\hline & $\%$ & $95 \% \mathrm{Cl}$ & $\%$ & $95 \% \mathrm{Cl}$ & $\%$ & $95 \% \mathrm{Cl}$ \\
\hline Noise from neighbors & 17.3 & $10.9-26.5$ & $8.0^{\star}$ & $7.4-8.7$ & $10.3^{\star}$ & $9.0-11.8$ \\
\hline Noise from ventilation system & 8.1 & $4.2-15.0$ & $3.5^{\star}$ & $3.1-4.0$ & $4.0^{*}$ & $3.1-5.0$ \\
\hline Traffic noise & 17.1 & $10.8-26.2$ & $6.1^{\star}$ & $5.6-6.7$ & $7.4^{\star}$ & $6.3-8.7$ \\
\hline Car exhaust & 11.2 & $6.7-18.1$ & $3.6^{*}$ & $3.3-4.1$ & $5.1^{\star}$ & $4.2-6.2$ \\
\hline Environmental tobacco smoke & 5.3 & $2.4-11.1$ & 3.6 & $3.2-4.1$ & 5.2 & $4.2-6.4$ \\
\hline Smell from street & 5.8 & $2.8-11.9$ & $1.8^{*}$ & $1.5-2.1$ & 2.9 & $2.2-3.7$ \\
\hline Soot & 4.4 & $1.9-9.8$ & $0.7^{\star}$ & $0.6-1.0$ & $1.1^{\star}$ & $0.7-1.7$ \\
\hline Dust & 17.2 & $10.8-26.4$ & $5.4^{*}$ & $4.9-5.9$ & $8.4^{\star}$ & $7.2-9.8$ \\
\hline Stuffy, "bad" air & 15.6 & $9.4-24.9$ & $4.1^{*}$ & $3.7-4.6$ & $5.7^{\star}$ & $4.7-6.9$ \\
\hline Low room temperature & 15.8 & $9.6-24.9$ & $5.5^{\star}$ & $5.0-6.1$ & $6.6^{\star}$ & $5.6-7.9$ \\
\hline Dry air & 11.9 & $7.1-19.1$ & $5.2^{\star}$ & $4.7-5.7$ & 7.8 & $6.6-9.2$ \\
\hline
\end{tabular}

* $\mathrm{P}<0.05$ in the comparison to the group reporting hypersensitivity to electric or magnetic fields.

Table 7. Factor structure and factor loadings for symptom indices in the reference group and the group reporting hypersensitivity to electric or magnetic fields. (hypersensitivity group = hypersensitive to electric or magnetic fields)

\begin{tabular}{llc}
\hline Symptoms & \multicolumn{2}{l}{ Loadings on factors } \\
\cline { 2 - 3 } & Referents & $\begin{array}{c}\text { Hypersensi- } \\
\text { tivity group }\end{array}$ \\
\hline Factor I: neurovegetative symptoms & & \\
Fatigue & 0.64 & 0.69 \\
Sense of heavyness in the head & 0.77 & 0.77 \\
Headache & 0.64 & 0.70 \\
Nausea or dizziness & 0.47 & 0.54 \\
Difficulties to concentrate & 0.50 & 0.64 \\
Factor II: eyes and airways & & \\
Eye irritation & 0.40 & 0.56 \\
Runny or stuffy nose & 0.62 & 0.70 \\
Impaired sense of smell & 0.49 & 0.52 \\
Hoarse or dry throat & 0.63 & 0.64 \\
Coughing & 0.57 & 0.62 \\
\hline
\end{tabular}

with varimax (orthogonal) rotation in the analysis of the reference group. We used the oblique method of rotation promax, which does not require factors to be independent, for scale evaluation in the group reporting hypersensitivity to electric or magnetic fields. The analysis identified two factors in the reference group. Factor I represented neurovegetative symptoms (fatigue, heaviness in the head, headache, nausea or dizziness, and difficulties in concentrating). Factor II represented eye and airway complaints (table 7). The factor structure identified for the reference group was replicated in the group that reported hypersensitivity to electric or magnetic fields. The two methods of rotation (varimax and promax) yielded similar results; table 7 shows only the outcome of the varimax rotation. Skin complaints were not associated with either factor. The symptom "feeling of pressure in ear" was weakly associated with factor II in the reference group (factor loading 0.40 , varimax rotation) and weakly associated with factor I in the hypersensitivity group (factor loading 0.40 , promax rotation). The total variance explained by the two factors was $37 \%$ for the referents and $48 \%$ for the hypersensitivity group. The Cronbach alpha coefficients were 0.8 for factor I and 0.7 for factor II for the reference group. In the case of the neurovegetative index, the mean index scores were 1.6 for the referents and 1.9 for the hypersensitivity group. With the eyes and airways index, the mean index scores were 1.4 for the referents and 1.7 for the hypersensitivity group.

\section{Discussion}

This is the first population-based study of the prevalence of self-reported hypersensitivity to electric or magnetic fields in Sweden. We compared subjects reporting this complaint with those who did not, with a subgroup also reporting amalgam-related symptoms, and with persons suffering from asthma or hay fever.

Although information from cross-sectional studies must be interpreted with caution, the rather large proportion of respondents who report hypersensitivity to electric or magnetic fields is noteworthy. An extrapolation from the results of the survey would suggest that 16000 to 22000 of the 1.3 million people in Stockholm County (among these age groups) would report this hypersensitivity. No causal relationship between electric or magnetic fields lower than current reference levels 
and skin or neurovegetative symptoms has yet been proved. But the results of our study may be an indication of widespread concern among the general population about health risks that stem from electric and magnetic fields. The higher percentage of women reporting hypersensitivity to electric or magnetic fields agrees with the results of earlier occupational studies (3).

Hypersensitivity to electric or magnetic fields can be interpreted as one facet (or an alternate manifestation) of self-reported environmental illness. The reported prevalence of environmental illness, defined as hypersensitivity to electric or magnetic fields in this study, was lower than the reported prevalence $(6.3 \%)$ of physician-diagnosed environmental illness or multiple chemical sensitivity in a 1995 American survey (13). The application of the criterion of physician-diagnosed environmental illness, the perception of having an extraordinary sensitivity to chemicals together with health problems that interfere with daily activities, was met by $0.6 \%$ of the respondents in the American survey. Amalgam intolerance, multiple chemical sensitivity, and hypersensitivity to electricity are not accepted as medical diagnoses in Sweden; physicians use symptom diagnosis instead. Although our study did not provide information on the occurrence of disabilities that stem from perceived hypersensitivity to electric or magnetic fields, we observed that a smaller percentage of persons in that group were employed.

Our study found an association between reported hypersensitivity to electric or magnetic fields and selfreported traditional allergies and hypersensitivities. The increase in reported allergies or hypersensitivities was especially striking with regard to their less common causes in the general population (ie, mite, mold, and gluten). Furthermore, there was a substantial overlap between the groups that reported hypersensitivity to electric or magnetic fields and amalgam intolerance. The prevalence of allergies and hypersensitivities was especially high in the subgroup that reported both hypersensitivity to electric or magnetic fields and amalgam-related complaints, although there was no indication of a higher prevalence of asthma or hay fever in this subgroup. One in three persons in this subgroup reported gluten intolerance. The prevalence of celiac disease in the general population has been estimated at about 1 in 200 [ie, $0.5 \%$ (15)], which was similar to the reported prevalence of gluten intolerance in the reference group. It would be interesting to explore whether studies of immune parameters confirm the observed higher prevalence of allergies and hypersensitivities in the hypersensitivity group.

Our results support earlier indications of similarities among groups that report different kinds of environmental illness. In an American study of multiple chemical sensitivity, the proportion of respondents who reported a change in tolerance for allergens and foods was more than twice as high in the group that reported chemical odor intolerance than in the reference group (6). Another American study showed that persons with chemical odor intolerance were four times as likely to report asthma and $72 \%$ more likely to report a history of hay fever (16). Our present study also showed a higher prevalence of asthma and hay fever in the hypersensitivity group.

Persons who report environmental illness sometimes express disappointment that standard health care institutions are unresponsive to their expectations with regard to diagnosing environmental illness or recommending intervention. As a result, persons who suffer from perceived environmental illness may seek traditional health care less often than others. They may also suspect that they are suffering from various types of allergies, whereas persons with similar problems but not believing that they suffer from environmental illness are more likely to have visited a doctor and learned that they were not allergic after all. In that case, the latter group would report a lower incidence of allergies. But it appears improbable that such a pattern could explain the variations in health problems observed in our study, particularly when the higher prevalence of reported hypertension and colds is accounted for.

The hypersensitivity group also reported being disturbed by various environmental factors (with the exception of environmental tobacco smoke) in the home to a considerably greater extent than the rest of the respondents. Previous studies of groups that report environmental illness have indicated hyperresponsiveness of the central and autonomic nervous systems. Flickering light (comparable with modulation in fluorescent tubes) was shown to trigger higher amplitudes in the brain cortex response in subjects who report hypersensitivity to electric or magnetic fields than in a reference group (17). In a study of office workers with VDU-associated skin complaints, Arnetz and his co-workers observed higher levels of the stress-related hormones prolactin and thyroxin in this group than in a reference group, although only on workdays (18). A provocation study showed that the subjects with hypersensitivity to electric or magnetic fields manifested greater differences in skin temperature between the two sides of the face than the reference group did (2). Differences in vegetative system functions and control of the autonomic nervous system have also been discussed in connection with multiple chemical sensitivity $(19,20)$. Hyperresponsiveness to several different factors could explain these findings - as well as the observations of our study, including an increase in all symptoms and higher reported disturbances from various environmental factors. A two-step model has been proposed for environmental illnesses such as multiple chemical sensitivity and 
hypersensitivity to electricity (21). After initiation, the limbic system and other areas of the brain become sensitized and hyperreactive to various environmental stimuli.

In a study of multiple chemical sensitivities a significantly larger proportion of sensitive groups than the general population reported complaints in every category (eye, nose, throat, gastrointestinal, systemic, musculoskeletal, central nervous system, headaches, dermatological, lower respiratory, genitourinary, and circulatory) (6). Our study showed similar results.

We were not able to identify a specific symptom profile for the group that reported hypersensitivity to electric or magnetic fields. The factor structure identified for the referents was replicated in the hypersensitivity group. But the total explained variance was less than $50 \%$. The symptom indices that were based on the identified factors could still be of value. Groups that report various forms of environmental illness are heterogeneous, and the use of indices facilitates comparisons among them. The factor representing neurovegetative symptoms was similar to the factor constructed by a previous study (11). Skin complaints were common both in the hypersensitive group and for all the referents. But the greater frequency of skin symptoms among the persons who reported hypersensitivity to electric or magnetic fields was apparent.

Previous studies of hypersensitivity to electricity have recruited study groups from either workplaces or among people who seek medical help for perceived hypersensitivity to electricity. Besides essentially confirming previous findings regarding symptoms (11) and gender distribution $(3,4)$, this population-based study provides new information about reported health problems in this group and the prevalence in the population at large.

Although the number of persons who reported environmental hypersensitivities in our study was rather small, the results are remarkably consistent. The group that reported hypersensitivity to electric or magnetic fields scored higher than persons not reporting this hypersensitivity for all other types of allergies, hypersensitivities, disturbance factors (except for environmental tobacco smoke), and symptoms. The hypersensitivity group also reported a significantly greater prevalence of colds more frequent than twice a year, and a higher percentage reported physician-diagnosed hypertension. Although this study does not permit conclusions about the reasons for the high scores among the hypersensitive groups, a fairly safe assumption is that these persons experience many more health problems. This study could not explore the prevalence of disability due to this perceived hypersensitivity, but the group appeared to have a lower capacity for work. There is a great need for further research about these vulnerable persons.
Another important area of further exploration is the indicated higher prevalence among people born outside the Nordic countries and people in low-income brackets.

\section{References}

1. Portier CJ, Wolfe MS, editors. Assessment of health effects from exposure to power-line frequency electric and magnetic fields - NIEHS Working Group Report. Research Triangular Park (NC): National Institute of Environmental Health Sciences, 1998. NIH publications no 98-3981.

2. Bergqvist U, Vogel E, editors. Possible health implication of subjective symptoms and electromagnetic fields: a report by a European group of experts for the European Commission, DG V. Solna (Sweden): National Institute for Working Life, 1997. Arbete och Hälsa 1997:19.

3. Hillert L, Kolmodin-Hedman B. Hypersensitivity to electricity: sense or sensibility? J Psychosom Res 1997;42: 427-32.

4. Bergdahl J. Psychologic aspects of patients with symptoms presumed to be caused by electricity or visual display units. Acta Odontol Scand 1995;53:304-10.

5. Fiedler N, Kipen H. Chemical sensitivity: the scientific literature. Environ Health Perspect 1997;105 suppl 2:409-15.

6. Davidoff AL, Keyl PM. Symptoms and health status in individuals with multiple chemical sensitivities syndrome from four reported sensitizing exposures and a general population comparison group. Arch Environ Health 1996;51:201-13.

7. Langworth S. Experiences from the amalgam unit at Huddinge hospital - somatic and psychosomatic aspects. Scand J Work Environ Health 1997;23 suppl3:65-7.

8. Furhoff AK, Tomson Y, Mircea I, Bagedahl-Strindlund M, Larsson KS, Sandborg-Englund G, et al. A multidisciplinary clinical study of patients suffering from illness associated with release of mercury from dental restorations. Scand J Prim Health Care 1998;16:247-52.

9. World Health Organization (WHO). Indoor air pollutants: exposure and health effects. Copenhagen: WHO, 1983. WHO EURO reports and studies 1983:78.

10. Mayou R. Somatization. Psychother Psychosom 1993;59: 69-83.

11. Hillert L, Kolmodin Hedman B, Söderman E, Arnetz BB. Hypersensitivity to electricity: working definition and additional characterization of the syndrome. J Psychosom Res 1999;47:429-38.

12. Bergdahl J, Anneroth G, Stenman E. Description of people with symptoms presumed to be caused by electricity or visual display units — oral aspects. Scand J Dent Res 1994;102:41-5.

13. Kreutzer R, Neutra RR, Lashuay N. Prevalence of people reporting sensitivities to chemicals in a population-based survey. Am J Epidemiol 1999;150:1-12.

14. Fransson K. Elöverkänslighet bland TCO-förbundets medlemmar [Hypersensitivity to electricity among members of the Swedish Confederation of Professional Employees]. Stockholm: The Swedish Confederation of Professional Employees, TCO Development; 1996.

15. Feighery C. Coeliac disease. BMJ 1999;319:236-9.

16. Baldwin CM, Bell IR, O'Rourke MK. Odor sensitivity and respiratory complaint profiles in a community-based sample with asthma, hay fever and chemical odor intolerance. Toxi- 
col Ind Health 1999;15:403-9.

17. Sandström M, Lyskov E, Berglund A, Medvedev S, Hansson Mild K. Neurophysiological effects of flickering light in patients with perceived electric hypersensitivity. J Occup Environ Med 1997;39:15-22.

18. Berg M, Arnetz BB, Lidén S, Eneroth P, Kallner A. Technostress: a psychophysiological study of employees with VDUassociated skin complaints. J Occup Med 1992;34:698-701.

19. Wang T, Hawkins LH, Rea WJ. Effects of ELF magnetic fields on patients with chemical sensitivities. In: Simunic D, editor. COST 244 meeting on electromagnetic hypersensitiv- ity. Graz (Austria): European Cooperation in the Field of Science and Technical Research Project 244, 1994:123-32.

20. Bell IR, Schwartz GE, Bootzin RR, Wyat JK. Time-dependent sensitization of heart rate and blood pressure over multiple laboratory session in elderly individuals with chemical odor intolerance. Arch Environ Health 1997;52:6-17.

21. Arnetz BB. Model development and research vision for the future of multiple chemical sensitivity. Scand J Work Environ Health 1999;25:569-73.

Received for publication: 16 May 2001 